\title{
The datafication of early years education and its impact upon pedagogy
}

by Guy Roberts-Holmes and Alice Bradbury

UCL Institute of Education, London

\begin{abstract}
This paper raises important questions about whether the increasing control of early years education through performance data is genuinely a means for school improvement. This composite article, based upon the previously published work of Roberts-Holmes (2015) and Roberts-Holmes and Bradbury (2016), examines the pervasiveness of attainment data in early years education professional activity, its impact on early years teachers' consciousness and identity, and the narrowing and instrumentalisation of early years pedagogy. The authors argue that, rather than improving quality, the current obsession with performance data and its stretch down the age range has the potential to undermine the foundations for children's personal development and learning. The article also points to the ways in which a triage effect (Gillborn and Youdell, 2000) has led to the neglect of some children in order to push targeted children over specific performativity hurdles. The discussion applies Foucault to the early education sector in England, and builds upon other early childhood researchers such as Moss (2014).
\end{abstract}

Keywords Data, early years, accountability, governance.

\section{Introduction}

Aims for early years care and education are increasingly being framed in terms of 'school readiness' and preparation for adult economic life as potential human capital, within a global education 'race' which begins in pre-school.

If we want our children to succeed at school, go on to university or into an apprenticeship and thrive in later life, we must get it right in the early years. More great childcare is vital to ensuring we can compete in the global race, by helping parents back to work and readying children for school and, eventually, employment (DfE 2013, 5).

The evidence in this paper suggests that some early years teachers' pedagogy is narrowing to ensure that children succeed within specific testing regimes which interpret literacy and numeracy in very particular and limited ways. Moreover, this accountability regime has the tendency to subvert the early years from being a unique child-centred and play-based educational stage in its own right, to that of subserviently preparing children for school, and subsequently as 'human capital' for employment (Bradbury 2012a; Moss 2012). It is argued that the intensification of high stakes performance data increasingly acts as a 'meta-policy' steering early years pedagogy 'from a distance' (Lingard, et al, 2013:541), and has the effect of undermining some early years 
professionals' deeply held child-centred pedagogical values (Roberts-Holmes and Bradbury, 2016).

\section{Foucault goes to nursery}

Although writing in a different era in terms of the proliferation of digital data, many of Foucault's concerns in relation to governance and self-governance can be applied to the modern education system. Data-based accountability governs education (Ozga et al, 2011) by operating as a technology that is an 'indefinite discipline, an interrogation without end' (Foucault, 1977, 227). Through making schools visible and knowable, networks and databases have become dominant techniques of governing (Lingard et al, 2013; Williamson, 2014b) so that comparative data 'are the technologies of governing' and key to the 'governance turn' (Fenwick et al 2014,6) such that digital data has become 'interwoven' with the governance of education and represents an artefact of 'digital governance'. These processes of governance through data increasingly apply to the early years sector (Roberts-Holmes and Bradbury, 2016).

At the same time, we should recognise that this situation is not, ultimately, fatalistic. Foucault (1977) argued that governance involves the use of a range of technologies to exercise power over the actions of individuals, who both willingly comply through processes of self-governance, and resist, 'He who is subjected to a field of visibility, and who knows it, assumes responsibility for the constraints of power; he makes them play spontaneously upon himself; he inscribes in himself the power relation in which he simultaneously plays both roles; he becomes the principle of his own subjection' (Foucault, 1977 202-203).

There is a substantial literature internationally concerning the increasing regulation of the education and care of young children, and particularly the power of discourses of accountability and 'quality' (Ozga, 2009, 2011, 2013; Moss, 2014). Earlier we have noted how early childhood workers become self-governing professionals under the gaze of simplified governing data (Bradbury, 2013; Roberts-Holmes, 2015).

Within all this, early years becomes the starting line for measurements of school 'quality', set within the broader 'global economic race'; young children are constructed as fertile ground for future education and employment. Similarly, we argue that calculable market place economics has the tendency to draw the wider social purposes of early years education into an economic and industrial policy (Ball, 2013) so that early years education is involved in 'the politics of data' (Selwyn, 2015a): data are not neutral constructions used in neutral ways, but powerfully influenced by particular concepts of what can be measured and analysed.

Moving on to the level of pedagogy, our research builds on Moss (2014) who argues that 'complexity and messiness, diversity and context, the social and the cultural must and can be controlled, reduced and tamed, spurred on by the belief that there must be one right answer for every question, one calculable rate of return on any investment' (Moss, 2014, 66). 


\section{Methodology}

This report relates empirically to two studies. In the first (Roberts-Holmes, 2015) email correspondence, telephone interviews, and focus group and individual interviews were conducted with 20 Reception teachers studying for Early Years Education Master's degrees. This sample included a local authority early years advisor, who enabled us to observe an Early Years Coordinators' meeting of nine early years teachers.

In the second (Roberts-Holmes and Bradbury, 2016) two researchers studied three different types of English state provision: a Children's Centre, a Nursery and Reception class in a primary school, and a combined Nursery School and Children's Centre. Three three sites were an opportunity sample since access was based on some research relationships from the earlier study. We interviewed several staff in each, held focus group discussions and conducted limited observations. Documentary data including attainment spreadsheets were studied. In addition, we interviewed a local authority advisor unconnected to the three sites. The sites catered for a broad social range, but with a large number of disadvantaged families, and the children's centre included a range of provision for children and parents including 'stay and play' sessions, midwifery services and postnatal care.

Following the interviews during this study, a reception class and a nursery class, in two different schools and local authorities, were observed for a half day a month for the whole school year. Detailed field notes and observations of pedagogy were made, particularly focusing upon the time teachers spent on maths and phonics and way in which the class was organised to facilitate this. The data was reduced to meaningful codes and names were assigned to each code leading to recurring and prevalent themes (Creswell 2007).

\section{Overwhelmed by 'datafication'}

Across the various sites the teachers articulated how they were increasingly subjected to the demands of data production; they were aware of the pitfalls, cynical about the purposes of data, and yet, in an intensified form of the findings of previous research (Bradbury, 2012b), they found their working lives constrained by exhaustive demands for the production and analysis of data.

The collection and analysing of data is just too overwhelming. It makes you constantly think of how to improve it and what to do with this group and how to plug this hole and that one. I fill in trackers frequently and I feel a personal pressure to make them progress. (Reception teacher, Primary School).

Rather than challenging or subverting such regulation this teacher self-governed by intensifying her workload to demonstrate constant and uninterrupted progress and development for all children at all times. Every child must be 'tracked' to ensure they are moving forwards. This required ever more detailed data, to show their incremental progress. 
Data production was part of an elaborate performance for Ofsted; inspection has always required this performance (Perryman, 2009) but there was now a need to engage in that performance throughout the year, not just when Ofsted arrive. Thus the data production and analysis spreads in terms of time, as well as in its reach.

You have to track children all the time and I have to add everyone's data at the end of each term to the school tracker. Have they performed appropriately and if not why not and what interventions are going to have go in? Nobody's allowed to fall behind. The tracking begins from Nursery in the Prime Areas and right through to year 6 . If you are exceeding at the end of Reception you have to show that you are exceeding at the end of KS1 and if not then we are not doing our job. (Deputy Head teacher, Primary School).

This is the disciplinary power of uncertainty, where no one can be content but instead has to be constantly self-reforming, self-improving and showing progress. The constant need to show progress involved the production of ever more complex grids, charts, graphs and tables with acronyms related to a colour-coded, age-based system of points the children can attain, and the security of this attainment in relation to their age, recorded as 'developing', and 'secure'. Such high stakes 'compliance' data was needed for the purposes of regulatory inspection and teachers contrasted it with the more 'useful data' (Selywn, 2015) in the form of narrative and formative assessments based on teachers' observations.

The Hopetown Children's Centre Manager argued that collecting vast amounts of metadata was simply for accountability and not about pedagogy.

'So there's two kinds of data, the metadata and the micro and they get mixed up which suggests people don't understand what they are for. Large scale data is not useful for pedagogy... It's just an accountability tool. The large scale whole school data is the same in every school in the country so why should we measure it when there's nothing we can do about it? It's much better to focus on the detailed qualitative data that focuses upon a child's interests and how to develop and build upon that'. (Hopetown Children's Centre Manager).

The compliance data grids that early years teachers had to constantly produce for children from age two acted as the 'malicious minutiae' (Foucault, 1977, 226) of regulatory surveillance and had become a 'relentless and inescapable' (Ozga 2009, 154) feature that make up early years education. For the early years teachers in the study, the relentless filling in, monitoring, and evaluation of 'trackers', assessment sheets and profiles both handwritten and on the computer constituted the techniques of governmentality as they struggled with the constant necessity to improve performance.

Where do you stop with it because there is so much of it! Health data, education data, family support data and well-being data and to be perfectly honest I just can't cope with that 
much data all the time! So I have put people in place people who can manage that data. (Headteacher, Nursery School and Children's Centre).

Similarly to Selwyn's et al's (2015) interviews with Australian secondary school teachers, this nursery head teacher 'begrudgingly accepted' digital governance 'with indifference rather than cynicism or resistance'. As early years multi-agency working expanded, the headteacher agreed that accountability was a necessary requirement but that at the same time he was overwhelmed and 'burdened with the responsibility to perform' (Ball and Olmedo, 2013, 88) by constantly having to improve performance across an ever increasing range of education and health data streams. However, the headteacher did not specifically challenge the increase in early years regulation and accountability as it was intimately bound up with his professionalism. Ironically, the Nursery teacher promoted to manage the data was a former accountant who had changed profession specifically to work with children and now found herself again working with numbers. Within the high stakes performativity culture, data production, tracking and mining had became 'the new technical professionalism' (Ball et al 2012, 523).

\section{The Prioritisation of Institutional Performance, 'The school's outstanding status must be maintained'}

The interviews revealed that the various centres were firmly located within the 'meta-narrative of schooling as performances' (Ball et al, 2012, 515).

I should be in classrooms supporting colleagues but I spend far too much time looking at assessment data and it is for proving to OFSTED that we are great. I'm an expert at speaking to OFSTED and tell them everything they want to know about data in our school. But actually I would be far more effective if I were in class and the children would benefit more. But I get patted on the head by OFSTED because I really know that data.... The head's job rests on whether the data is good or bad, so this in turn puts masses of pressure all the way down through the school and into the early years'. (Deputy Head teacher, Primary School; our emphasis).

The consequences of not producing the 'right' data for Ofsted was severe, so that the data driven 'regimes of truth' such as 'tracking progress', 'reducing the gap' and 'value added' took precedence over her time. Indeed, subsequent to this study, legislation has increased the disciplinary consequences of failing to collect the 'right' accountability data (DfE 2015). This teacher's enactment of being a data 'expert' replaced 'what is important, with what is measurable' (Nikel and Lowe 2010,596 ) so that numerical expertise 'trumped' classroom experience and knowledge.

As a further example, one of the Reception teachers wanted the children to play with maths construction equipment but was told that the Head teacher wanted more 'formal maths input because sacrifices had to be made to ensure that the school's outstanding status be maintained.' 
Here the wealth of research (Broadhead, 2006) demonstrating the value of play based approaches to learning was 'sacrificed' at the altar of 'outstanding' grading so that the enactment of performance data became a professional necessity.

\section{Datafication and hierarchies of power}

The Reception teacher above noted that 'unfortunately data is often used by others to direct us and to tell us what to do and the danger is that it's used by others and not for our agenda'. This reception teacher found that the accountability data he collected was recycled back to him as percentage targets which had the effect of steering his pedagogy. Even enlightened forms of assessment are subverted and distorted by this environment. The current holistic baseline, which measures children's progress against Development Matters in the Autumn term, is sent to the Local Authority (LA) who data mine it and predict where the children could be for their summative Good Levels of Development (GLD) at the end of the Reception year in the summer term.

'Schools currently do a baseline on entry to Year R, and send it to us and we carefully analyse the baseline and do a projected Good Level of Development. Schools use that indepth analysis of the data as a support and challenge to drive improvements forward. We set a percentage projection but it is a very crude one - so they need to go back and check it and drill right down into it to set challenges for themselves'. (Local Authority Advisor; our emphasis).

At the children's centre, tracking data from the age of two was fed to the local authority for tracking and prediction purposes:

'We record how the children enter when they are 2, so we have a baseline and then throughout the year we do 3 assessments with the children at set points and then compare them with each other to check that they are on track are making progress. You have to show that you have made 'value added' by the time they reach end of Reception. The LA are using that information to predict how 2 year olds are going to do at the end of FS, KS1, and KS2'. (Deputy Manager, Children's Centre).

Data production, exchange, mining and prediction had become central within the relationship between the LA and the school. Data packs were used to compare and rank, locally and nationally, with the intention of 'naming and shaming'.

'We 'name and shame' by showing all the school names. Some schools didn't have any children at 'working above the expected level' so you say 'well your statistical neighbour has this \% so how come you haven't?' And they think 'l'd better go back and have another look at that... It does challenge them and that's why we do it. It's accepted and l've not had any adverse comments. It was agreed by the Heads that they wanted that'. (Local Authority Advisor). 
Foucault $(1977,181)$ suggests that such hierarchical ranking of students, or in this case schools, 'serves as a reward or punishment' disciplining schools through ranked competitive performances. This leads to 'a highly reductionist' version of school improvement.

This process of getting teachers to 'go back and have another look' results in a process of governing through a 'constant self-evaluation' of performance (Fenwick et al 2014:5). Collegiality between settings became replaced by competition between 'statistical neighbours', assisted by various data packs and dashboards.

\section{The impact on teachers, teaching and children}

Subjective judgements on very young children, translated into numerical form, have become a useful commodity in the monitoring of current and predicted early years educational performance (DfE, 2014). Specifically, the early years has become increasingly drawn into the school 'delivery chain' (Ball et al. 2012, Moss 2014) partly enabled by the increased circulation and flow of digital data through which teachers measure performance between the input of the nursery to the end of primary school and, recently, explicitly through to exams at age 16.

Through this governing process early years local and contextualised professionalism is shifted towards producing objective numerical data for comparison within a highly centralised national system. Williamson (2014), argues that databases, reinvent teachers and children 'into data that can be measured, compared, assessed and acted upon' and suggests that children become reconfigured as 'miniature centres of calculation' (Williamson, 2014, 12). This notion of being reduced to pieces of data is demonstrated by Hutchings (2015) who examined the impact of accountability upon children, including the early years; 'it is deeply saddening that some of the pupils interviewed feel reduced to a statistic - jumping through hoops for the benefit of others, and with no space to discover the creative and positive learning that school should provide' $(2015 ; 1)$. Within this there is a sense that young children could become reduced to the school's statistical 'raw materials' that are mined and exploited for their maximum productivity gains.

Even very young children are being labeled as 'failing', and indeed, following the phonics test at the end of Year 1, headteachers are required to notify parents whether their child has passed or failed. The detrimental effects upon children's well-being were demonstrated by one teacher's comments:

I am now pushing information into three-year-olds rather than developing meaningful relationships. Even in the nursery I now feel that pressure. If a child doesn't recognize a number or a letter I go "aggghhh' and hold my breath. I have to remind myself the child is three and not yet ready for it. (Reception teacher, Primary school).

This nursery teacher struggled as he attempted to find the balance between the discourse of institutional performance and the needs of a three-year-old child. Here the construction of performance data in the nursery to meet the demands of neo-liberal economic productivity and 
accountability was contrasted with the needs of this particular child for whom such knowledge was inappropriate.

\section{Professional responses}

The data is not allowed to simply 'speak for itself' but is further processed and articulated through the inspection agency Ofsted. This creates a further pressure to accumulate data:

We're totally data driven. If the data is good Ofsted leave us alone but if the data is poor they drill right down into everything. We'll be punished if we have poor data, so obviously it's a huge huge pressure to get the data looking good. Ofsted take the data from Year 6 and work back and see where they were in Year 2 and Reception. So it has really influenced thinking. (Primary Deputy Head)

The process involves reading the data sets in a direct line from Year 6 back to Reception. Such a simplistic, and crude reading of data, with harsh disciplinary consequences if targets were not met, served to ensure the head teachers focused their efforts on producing the expected data from the youngest children in the school. If they were able to orchestrate such a feat, they bought their 'freedom' from surveillance for a particular time.

Two stances were noticed among headteachers in the face of external pressures from local authorities or Ofsted. Thus whilst one head told her early years staff to be more formal in their teaching, another tried 'to protect' the holistic early years pedagogy. In this latter school, the nursery teacher confidently stated that he 'did the phonics, but then tucked it away to get on with the real business of being with the children'. However, other early years teachers felt obliged to 'cynically comply' (Bradbury 2013: 124).

It's all based on data. Ofsted are saying that if the teaching is good the data should be good and if there's bad teaching there is bad data'. So the data is driving the pedagogy. (Early Years Advisor).

We have constant meetings looking at the data. It has become very clinical and children have just become numbers.... In this game, you gotta play the game. If you're being judged on a score - teach to it - you're a fool if you don't. You must teach to the test - that's the agenda.' (Reception Teacher).

Data has to be 'correct' for consumption by Ofsted and the local authority. Bradbury (2013) noted how the EYFS Profile scores were produced, managed and changed to be 'acceptable' for the local authority. The constant collection, production and delivery of data had become an enacted fantasy in which their investment in the fabrication is immense. At the same time, data-driven decision making becomes a marker of legitimacy. 


\section{The reductive focus on literacy and numeracy}

In the first study (Roberts-Holmes, 2015) 16 of the 20 teachers mentioned the increased difficulty of obtaining a sufficient grade in literacy and maths. It was evident from interviewing teachers that a utilitarian managerial decision around producing good data was leading teachers to focus upon maths and English.

Yes children have been targeted and put into differentiated groups for maths and phonics. Most children in primary schools are ability grouped so why wouldn't this pedagogy find its way into the EY? (Reception Teacher)

Formal learning is now coming down from Year 1, through Reception and into the Nursery class with the three year olds that I teach.... We were explicitly asked by our headteacher to make nursery 'more formal' which means more direct teaching of maths and phonics..... The philosophy and values of the EYFS are being eroded. (Nursery Teacher).

The assessment shift towards formal maths and phonics resulted in pedagogical shifts towards the replication of primary school performance culture. In the Reception class of one primary school, following pressure from the headteacher, the main activity during both the mornings and afternoons was teaching maths and phonics in both whole class and ability groups. Half the year group had failed the phonics test in Year One and were required to sit it again in Year Two. To appease Ofsted, these children were excluded from based lessons to receive intensive phonics booster classes. Ability grouping and differentiated learning is increasing in Reception and even Nursery classes. These are examples of how testing policy has had a 'reductive effect on the provision and experiences of schooling... as curriculum width is reduced to ensure the enhancement of test scores' (Lingard, et al 2013, 553).

The influence of Ofsted, in its role in the policy transmission process, involved criticising the nursery school because there was 'not enough teaching to emphasise the sounds that letters make and to extend children's understanding of number and mathematical language' in the early years (a direct quotation from the school's inspection report). The inspector's report, which included observations of three year old children who had been in school for just two weeks, mentioned 'phonics' and 'teaching letter sounds' seven times. This was given as the reason for grading the school 'good' (the most common grade) rather than 'outstanding', which, for private providers, can have serious financial consequences.

\section{Educational triage reaches the early years}

The term 'triage' was used by Gillborn and Youdell (2000) to refer to a process whereby secondary schools concentrated their attention on students just below the $\mathrm{C}$ borderline in order to maximise $A^{*}-C$ grades, to the neglect of higher and lower attainers. A similar process was apparent in the early years situations we researched: 
It's about who's going to achieve the GLD. So we say "they're easily gonna make it, thank you very much". And we say "they're never going to make it so go over there and have a nice time" and we look at the middle group. We target these children because they are the ones who may make it. It's the same as Year 6 SATS. So you put all your effort and intervention into those that are just below and it's a very unfair system. (Local Authority Early Years Advisor).

Thus, the higher achievers were left to succeed in their own, a low achieving group were regarded as 'hopeless cases', and a middle group given sufficient attention and support to raise them to the level designated 'good level of development'. In addition, one Reception teacher mentioned that some of the lower attainers were labeled Special Educational Needs (SEN) so as not to harm the teacher's performance data. This meant that other professionals became involved and therefore co-responsible. In such cases it could be argued that datafication constrains expectations of the child, who has to be classified as SEN in order to avoid the teacher suffering disciplinary consequences. However, not all teachers subscribed to such strategies, for example one child labeled as SEN was targeted to achieve a Good Level of Development.

Despite the Early Years Foundation Stage profile being broadly based and involving observation over time, the last stage involves children being graded 1, 2 or 3 for each strand of development. Each child has to reach a 2 in every strand in order to achieve Good Level of Development (GLD). Given the extra weight, and difficulty, of literacy and numeracy strands, children were identified who had $2 s$ in all strands but these. In this school, these children were then placed in a special Target Group so that the school could achieve its GLD target. This was not viewed as an ethical or principled decision but simply a utilitarian step to produce the required data.

This parallels a US study (Booher-Jennings 2005) in which children were colloquially labeled passers, bubble kids and foundation (or remedial) kid. Targets were set based on 'bubble kids' becoming 'passers'. Similarly, in England, the ability group regarded as normal in secondary mathematics was spreading into the final years of primary school, with similar triage (Marks 2012). Thus data production strategies for older aged children have 'cascaded down' (Moss 2012) into the early years and provide a stark example of early years schoolification, legitimated and naturalised by the necessity to produce 'good' data. Bradbury (2013) has suggested that the performativity culture within some early years settings is so intense that the teachers are encouraged to manipulate data to produce 'appropriate' results.

Within an increasingly constrained context, there was evidence that some of the early years teachers questioned, challenged and resisted the performativity culture and retained, where they could, their child centred focus. However, the intensification of early years governance has resulted in the 'datafication' of early years teachers and children in which the public and constant hierarchical ranking, ordering and classification of children, teachers and schools constrained such democratic pedagogical spaces, visions and possibilities. The evidence presented in this paper 
suggests that the early years is increasingly subservient to the demands of the Primary National Curriculum as the strictures of datafication limits some early years teachers' pedagogical interpretations of the EYFS. The teachers struggled to make sense of their deeply held child centred values espoused by the EYFS principles, curriculum and pedagogies and at the same time perform to the datafication requirements of the school readiness assessment regime.

Such policy intensification has pulled the early years ever more tightly into the state's regulatory and disciplinary 'gaze' so that teachers and children's 'visibility' has increased through the public displays of data. The 'swarm of disciplinary mechanisms' (Foucault 1977, 211) steering early years policy to meet assessment targets encouraged some teachers to adopt a pedagogy that prepared children to 'pass' tests. Within this discourse the production of 'good' data became a mark of legitimacy, worth and value. Early years teacher's 'values are challenged and displaced by the 'terrors' of performativity' (Ball 2003) which uses crude statistical measures and calculative apparatus and which increasingly frames their pedagogy. Complex holistic child centred principles, sensitive pedagogies and assessments were in danger of being marginalised as early years teachers were 'burdened with the responsibility to perform' and submit to a 'new' moral system' (Ball \& Olmedo, 2013:88) that has the potential to reduce the rich competent child (and teacher) to a 'measureable teaching subject' (Ball \& Olmedo 2013, 92). The 'datafication' of the early years suggests that it is in the process of becoming the first stage in a 'delivery chain' (Ball et al. 2012), passing 'appropriate' numeracy and literacy data higher up the data chain and into the primary and secondary school system.

\section{Acknowledgements}

Thanks to Professor Peter Moss' insightful advice on the two previously published papers on which this composite is based.

\section{References:}

Ball, S. 2003. "The teacher's soul and the terrors of performativity". Journal of Education Policy 18 (3): 215-228.

Ball, S. 2013. The Education Debate: Politics and policy in the $21^{\text {st }}$ Century. Bristol: Policy Press.

Ball, S., M. Maguire, A. Braun, J. Perryman, \& K. Hoskins, (2012). "Assessment technologies in schools: 'deliverology' and the 'play of dominations'. Research Papers in Education 27 (5): 513533.

Ball, S., \& A. Olmedo. 2013. "Care of the self, resistance and subjectivity under neoliberal governmentalities". Critical Studies in Education 54 (1): 85-96.

Booher-Jennings, J. 2005. "Below the bubble: "Educational triage" and the Texas accountability system". American Educational Research Journal 42 (2): 231-68.

Bradbury, A. 2012a. "Education policy and the 'ideal learner': producing recognisable learnersubjects through early years assessment". British Journal of Sociology of Education 34 (1): 1-19.

Bradbury, A. 2012b. 'I feel absolutely incompetent': professionalism, policy and early childhood teachers". Contemporary Issues in Early Childhood 13 (3): 175-186. 
Bradbury, A. 2013. Understanding Early Years Inequality: Policy, assessment and young children's identities. London: Routledge.

Broadhead, P. (2006) Developing an understanding of young children's learning through play, the place of observation, interaction and reflection British Educational Research Journal 32, (2) 191207

Creswell, J. 2007. Qualitative inquiry and research design: Choosing among fiveapproaches. London: Sage Publications.

Department for Education (DfE) 2013. "More Great Childcare. Raising quality and giving parents more choice". Accessed May 5, 2013.

https://www.gov.uk/government/uploads/system/uploads/attachment_data/file/219660/More_20Gre at_20Childcare_20v2.pdf

Department for Education. 2014. "Reforming assessment and accountability for primary schools". Accessed March 10, 2014.

https://www.gov.uk/government/uploads/system/uploads/attachment_data/file/297595/Primary_Ac countability_and_Assessment_Consultation_Response.pdf

DfE 2015 Subsequent to this research, the DfE's (2015) Education and Adoption Bill has further increased the disciplinary consequences of 'failure' to collect and produce the 'right' accountability data https,//www.gov.uk/government/news/up-to-1000-failing-schools-to-be-transformed-undernew-measures.

Fenwick. T., Mangez, E., and Ozga.J. (Eds) (2014) Governing Knowledge, Comparison, Knowledge-Based Technologies and Expertise in the Regulation of Education, (World Yearbook of Education 2014) (London, Routledge).

Foucault, M. (1977) Discipline and Punish, The Birth of the Prison (London, Penguin Books).

Gillborn, D., and D. Youdell, (2000) Rationing Education: Policy Practice reform and equity. Buckingham: Open University Press.

Gove, M. (2009) A comprehensive programme for state education. Available online at, http,//www.conservatives.com/News/Speeches/2009/11/Michael_Gove_A_comprehensive_progra mme_for_state_education.aspx

Hutchings, M. (2015) The Impact of Accountability Measures on Children and Young People, Emerging Findings. Available Online at, https,//www.teachers.org.uk/node/23627

Lawn, M. (2013) The Rise of Data in Education Systems, Collection, visualisation and uses. (Symposium Books).

Lingard, B., W. Martino, and G. Rezai-Rashti, (2013). "Testing regimes, accountabilities and education policy: commensurate global and national developments". Journal of Education Policy 28 (5): 539-556.

Marks, R. 2012. "I get the feeling that this is really unfair": Educational Triage in Primary Mathematics". Proceedings of the British Society for Research into Learning Mathematics 32 (2): 58-63.

Moss, P. (2012). (Ed) Early Childhood and Compulsory Education :Reconceptualising the relationship (Contesting Early Childhood). London: Routledge.

Moss, P. (2014) Transformative Change and Real Utopias in Early Childhood Education, A story of democracy, experimentation and potentiality. (Oxon, Routledge).

Nikel, J. and Lowe, J (2010) Talking of Fabric, A multi-dimensional model of quality in education Compare 40 (5), 589-605.

Ozga, J. (2009) Governing Education through data in England, from regulation to self-evaluation. Journal of Education Policy 24(2), 149-162.

Ozga, J., Dahler-Larsen, P. Segerholm, C. and Simola, H., (2011) Fabricating Quality in Education, Data and Governance in Europe (London, Routledge). 
Ozga, J. (2013). Accountability as a policy technology: accounting for education performance in Europe. International Review of Administrative Sciences. 79: 292.

Perryman, J. (2009) Inspection and the fabrication of professional and performative processes. Journal of Education Policy 24 (5), 611-631.

Roberts-Holmes, G.P. \& Bradbury, A. (2016) Governance, Accountability and the 'Datafication' of the early years in England. British Educational Research Journal.

http://onlinelibrary.wiley.com/doi/10.1002/berj.3221/abstract (Article first published online: 17 Feb 2016)

Roberts-Holmes, G.P. (2015). The 'datafication' of early years pedagogy: 'if the teaching is good, the data should be good and if there's bad teaching, there is bad data'. Journal of Education Policy, 30 (3), 302-315. doi:10.1080/02680939.2014.924561

Selwyn, N., Henderson, M. and Chao, S. (2015) Exploring the role of digital data in contemporary schools and schooling -'200,000 lines in an Excel spreadsheet' British Educational Research Journal. Available Online at, DOI, 10.1002/berj.3186

Williamson, B. (2014) Reassembling children as data doppelgangers, How databases are making education machine-readable Powerful Knowledge conference $16^{\text {th }}$ May 2014, University of Bristol. 